\title{
High-resolution aftershock observations in the source region of the 2004 mid-Niigata Prefecture Earthquake
}

\author{
Aitaro Kato ${ }^{1}$ and The Research Team of aftershock observations for the 2004 mid-Niigata Prefecture Earthquake ${ }^{2}$ \\ ${ }^{1}$ Earthquake Research Institute, University of Tokyo, Tokyo, Japan \\ ${ }^{2}$ Refer to an author list at the end of this paper
}

(Received December 22, 2006; Revised April 23, 2007; Accepted June 1, 2007; Online published August 31, 2007)

\begin{abstract}
We deployed an extremely dense temporal seismic network in the source region of the 2004 mid-Niigata Prefecture Earthquake (thrust fault) on October 23, 2004, Japan. The seismic network consisted of 145 temporary seismic stations within a $30 \mathrm{~km}$ squared and had been kept within approximately a month after the mainshock. High accurate hypocenters of 708 events were determined by inverting the arrival times using double-difference earthquake location algorithm. The aftershocks along the mainshock $\left(M_{\mathrm{w}}=6.6\right)$ and the largest aftershock $\left(M_{\mathrm{w}}=6.3\right)$ rupture zones are distributed on two $60^{\circ}$ westward-dipping planes, located approximately $5 \mathrm{~km}$ apart. Conversely, the Oct. 27 aftershock $\left(M_{\mathrm{w}}=5.8\right)$ occurred on an eastward dipping plane with a dip angle of $25^{\circ}$ that was conjugate to the mainshock fault plane. Most of aftershocks at both northeastern and southwestern edges occurred at shallow depths with eastward-dipping planes. Epicenters of aftershocks in the southwestern region are aligned along $\mathrm{N} 15^{\circ} \mathrm{E}$, and rotate approximately $20^{\circ}$ counterclockwise from the strike of the mainshock fault. This rotation of the aftershock alignments coincides with the rotation of anticline axes in the southwestern area of the source region. Furthermore, distributions of station corrections for a one-dimensional velocity model suggest that the seismic velocity at the western side of the Muikamachi-fault is lower than that at the eastern side. It is also inferred that the velocity structures in the hangingwall vary along the fault strike. The average velocity in the mainshock rupture area is higher than the periphery in the hangingwall, especially compared with the southwestern side of the hypocenter.
\end{abstract}

Key words: Mid-Niigata Prefecture Earthquake, aftershocks, hypoDD, station corrections, dense seismic observations.

\section{Introduction}

The 2004 mid-Niigata Prefecture Earthquake of $M_{\mathrm{w}} 6.6$ occurred in the backarc area of the main Japanese Island as a shallow inland earthquake at 17:56 (JST $=\mathrm{UT}+9$ hours) on October 23, 2004, causing serious seismic damage and landslides in and around the source region. The focal mechanism of this earthquake, determined by the centroids moment analysis (NIED: National Research Institute for Earth Science and Disaster Prevention), was of a reverse fault type with a strike of approximately $\mathrm{N} 35^{\circ} \mathrm{E}$ (Fig. 1). The mainshock was followed by significant aftershock activity, and the number of large aftershocks $(M>4)$ was significantly greater than that associated with other recent inland earthquakes in Japan (Aoki et al., 2005, Japan Meteorological Agency (JMA) catalog). Four especially large aftershocks $(M>6)$ occurred at 18:03, 18:11, and 18:34 (the largest aftershock) on October 23 and at 10:40 on October 27.

The focal area was located in the eastern margin of a thick Miocene-Pleistocene sedimentary basin (Niigata Basin), characterized by a NNE-SSW trended anticlinesyncline system that forms the Uonuma Hills (Yanagisawa et al., 1986) (Fig. 1). Basement rocks older than $30 \mathrm{Ma}$ are

Copyright (c) The Society of Geomagnetism and Earth, Planetary and Space Sciences (SGEPSS); The Seismological Society of Japan; The Volcanological Society of Japan; The Geodetic Society of Japan; The Japanese Society for Planetary Sciences; TERRAPUB. widely exposed on the eastern side of the basin. A structural boundary between the western basin and the eastern basement corresponds to the Muikamachi Fault (MU in Fig. 1) and its northeastward extension. Geological studies indicate that the thick sedimentary basin was formed in a rift structure with a normal fault system that developed during the extension stage of the Japan Sea (Sato, 1994). The normal fault system has subsequently been reactivated as a reverse fault system owing to a change in the tectonic stress regime from extension to compression. Surface folding has been well developed around the source region since 3.5 Ma.

In Japan, dense seismic telemetry networks have been deployed by the NIED, the JMA, and several universities; the average spacing of stations in the network is approximately $20 \mathrm{~km}$. However, in the case of the aftershocks associated with the mid-Niigata Prefecture Earthquake, these networks are insufficient for detailed study such as resolving dips of the fault planes ruptured by the mainshock and some large aftershocks. Consequently, several research groups in Japan deployed temporary seismic stations following the mid-Niigata Prefecture Earthquake. Intensive researches such as hypocenter relocations, focal mechanism, seismic tomography and imaging of reflection planes or scatterings in the crust, have been conducted by several groups using data recorded at temporary seismic stations (e.g., Sakai et al., 2005; Kato et al., 2005a; Okada et al., 2005; Shibutani et al., 2005; Matsumoto et al., 2005). 


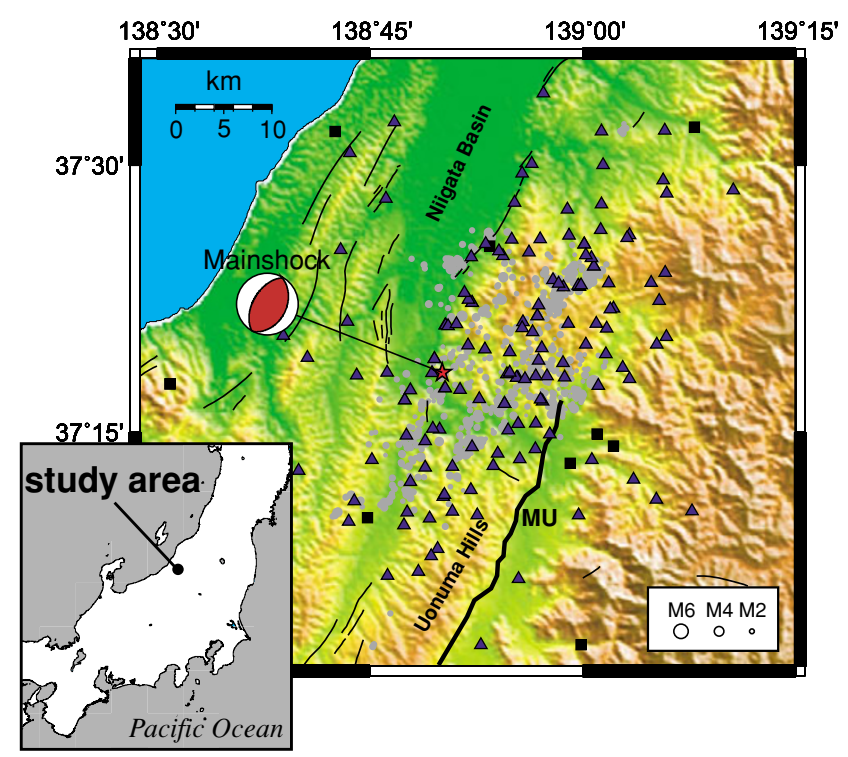

Fig. 1. Map of the seismic network installed in the source region of the 2004 mid-Niigata Prefecture Earthquake. The blue triangles denote temporary seismic stations, and the black squares denote permanent stations. Relocated aftershock hypocenters are shown as gray circles scaled to earthquake magnitude. The star denotes the epicenter of mainshock with moment tensor determined by NIED. The Muikamachi fault (MU) is shown by thick solid line, and the other major active faults are drawn as thin lines.

The results of the previous studies suggest that the complex structures associated with crustal stretching and folding have the potential to nucleate the mainshock and trigger a sequence of large aftershocks. However, more detailed analyses of the crustal heterogeneities associated with the nucleation of the mainshock are needed in order to elucidate the relationship between the crustal structures and the earthquake generation process. Since previous studies used seismic data derived from each research group, the spatial resolutions of crustal heterogeneities are obviously limited. In order to increase the spatial resolutions of crustal heterogeneities, we merge seismic data (arrival times and waveforms) for 708 aftershocks simultaneously observed at temporary stations installed by the research groups. Total number of the temporary seismic stations reaches 145 in and around the source region. High-resolution hypocenters of 708 events are determined by the double-difference relocation algorithm (Waldhauser and Ellsworth, 2000) using differential arrival times obtained by both the manually-picked and the waveform cross-correlation method. Hypocenters with high-accuracy are expected to be useful seismic sources to image the detailed crustal heterogeneities associated with the mainshock generation process in the future studies.

\section{Data and Earthquake Relocation Methods}

The seismic network in the present study consisted of 145 three-component temporary stations and 28 permanent stations located within a radius of $70 \mathrm{~km}$ from the center of the source region (Fig. 1). Each temporary seismic station was equipped with a $0.2-, 0.5-, 1-, 2-$, or, $4.5-\mathrm{Hz}$ seismometer, of which signals were recorded continuously at a sampling rate of 100,125 , or $200 \mathrm{~Hz}$, and with a GPS receiver to maintain the accuracy of the internal clock within $1 \mathrm{~ms}$. The permanent seismic stations observed waveforms at a rate of $100 \mathrm{~Hz}$. The format of merged waveform data is the win-format (Urabe, 1994).

Figure 2 shows history of the temporary seismic station deployment after the mainshock. The number of temporary stations increased with elapsed time. The spatial interval of stations is averaged to be roughly $2 \mathrm{~km}$ in the source region. We manually picked $P$ - and $S$-wave arrival times of observed events and visually read their first motion data from the waveforms. The arrival times for the $P$ - and $S$ wave reach 61,482 and 55,680, respectively. The data-size of waveforms and arrival times is roughly 1.6 GB.

To estimate the detailed hypocenter in the source region, the double-difference earthquake relocation technique ( $h y$ poDD) (Waldhauser and Ellsworth, 2000) was applied to the $P$ - and $S$-wave data. 'Double difference' denotes the difference between the arrival time residuals for two events obtained at a particular station; it corresponds to the difference between the observed and calculated arrival time differences. The double-difference relocation technique enables us to determine hypocenters with high-resolution, because effects of errors in the crustal structure and arrivaltime reading can be effectively minimized. We used differential arrival times obtained by the manually-picked and waveform correlation method.

In this analysis, we used the 708 aftershocks listed in the JMA catalog (for the period between Oct. 27 and Nov. 23) and observed by the very dense seismic network. The initial hypocentral locations of the events used for hypoDD analysis were determined by applying a maximum likelihood estimation algorithm (Hirata and Matsu'ura, 1987) to the observed arrival times. We employed one-dimensional velocity structure with a $V_{p} / V_{s}$ value of 1.73 as shown in Fig. 3. This model is derived from the average velocity structure between two velocity models for the northwestand southeast-side of the Muikamachi-fault (Sakai et al., 2005). From previous studies (e.g., Takeda et al., 2004), it is observed that at shallow depths of less than $3 \mathrm{~km}$, the northwest side of the Muikamachi Fault has a significantly lower velocity than that on the southeast. Furthermore, a station correction for each seismic station has been evaluated using average values of travel time residuals at each station (Fig. 4). Then, we adopted the station corrections to locate the initial hypocenters for hypoDD analysis.

Then, hypoDD algorithm was applied to the double difference data using the initial hypocenters evaluated through the procedures mentioned above. The differential arrival times for the manually picked $P$ - and $S$-wave reach 601,576 and 508,794. We also used the differential arrival times obtained by the waveform cross-correlation method (Schaff et al., 2004). For band-pass-filtered seismograms with a passband of $2-10 \mathrm{~Hz}$, the correlation measurements were conducted by aligning the nearest sample using $1.0 \mathrm{~s}$ window lengths beginning $0.4 \mathrm{~s}$ before the manually picked arrival time and then computing the double difference time to subsample precision using time-domain cross-correlation. We fitted a parabola in the time domain in the vicinity of the peak of the cross-correlation function (Schaff et al., 2004). We used a measurement of similarity to determine 

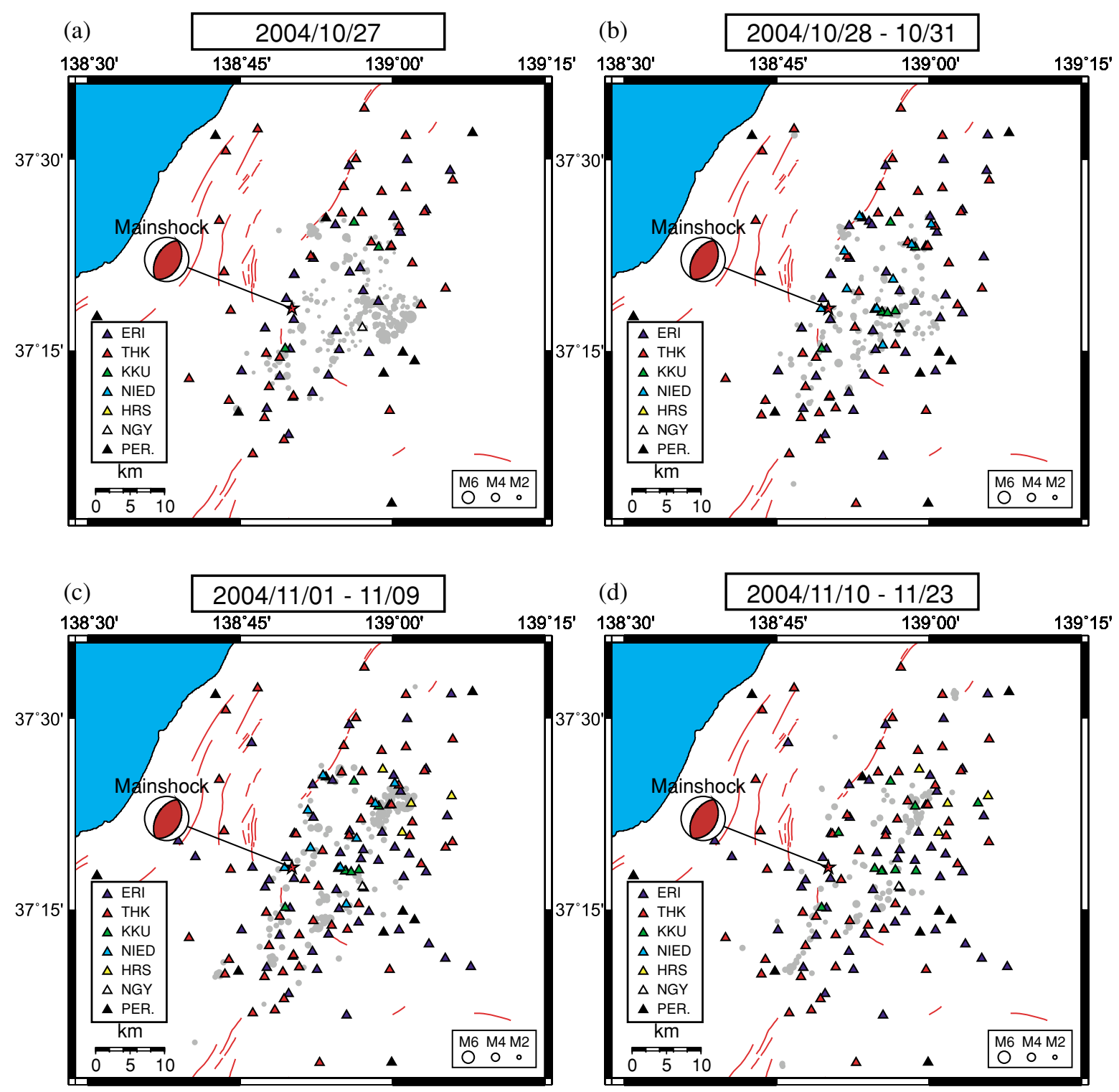

Fig. 2. History of the temporary seismic stations installed by each research group at four periods. (a) 2004/10/27. (b) 10/28-10/31. (c) 11/01-11/09. (d) 11/10-11/23. ERI: University of Tokyo. THK: Tohoku University, KKU: Kyoto and Kyusyu University, NIED: National Research Institute for Earth Science and Disaster Prevention, HRS: Hirosaki University, NGY: Nagoya University, PER: Permanent seismic station. Epicenters of aftershocks at each period are plotted as gray circles.

the threshold criteria for calculation of the double difference data; the normalized cross-correlation coefficient $\left(C_{\mathrm{c}}\right.$ : timedomain) $C_{\mathrm{c}}>85 \%$. After applying this cut-off, we were left with a data set of more accurate differential arrival times that contained 199,261 $P$-wave observations and 104,202 $S$-wave observations for use in hypoDD algorithm. We performed first 10 iterations during which we down-weighted the cross-correlation data in order to allow the manuallypicked data to draw the large scale picture of hypocenter distributions. For the next 5 iterations, we weighted the waveform cross-correlation data by a factor of 10 relative to the manually-picked data (Waldhauser and Ellsworth, 2000). The hypoDD algorithm inverted the weighted differential travel time residuals for event separation. The root mean square $(r m s)$ residuals decreased from $153 \mathrm{~ms}$ to 85 $\mathrm{ms}$, and from $120 \mathrm{~ms}$ to $25 \mathrm{~ms}$, for manually-picked and cross-correlation data, respectively.
In order to assess the reliability of the hypocenter calculations, we apply a statistical resampling approach to all events (bootstrap method; Shearer, 1997). For the final hypocenter, we calculated the synthetic arrival time data by adding random noises which are distributed within $\pm 80 \mathrm{~ms}$ for the manually picked data and $\pm 25 \mathrm{~ms}$ for the waveform cross-correlation data. We then relocated all events using these resampled data to determine a shift in the location from the final hypocenter. The process was repeated 200 times for each event. We calculated a variance-covariance matrix of the synthetic hypocenters to evaluate the uncertainty. The location error is defined as $\sigma$ ( $\sigma$ : standard deviation for the amount of the shifts) for each direction, which contains $68 \%$ of the relocated events with resampled data. Relative location errors in the horizontal and vertical directions are averaged to be $40 \mathrm{~m}$ and $80 \mathrm{~m}$, respectively. 


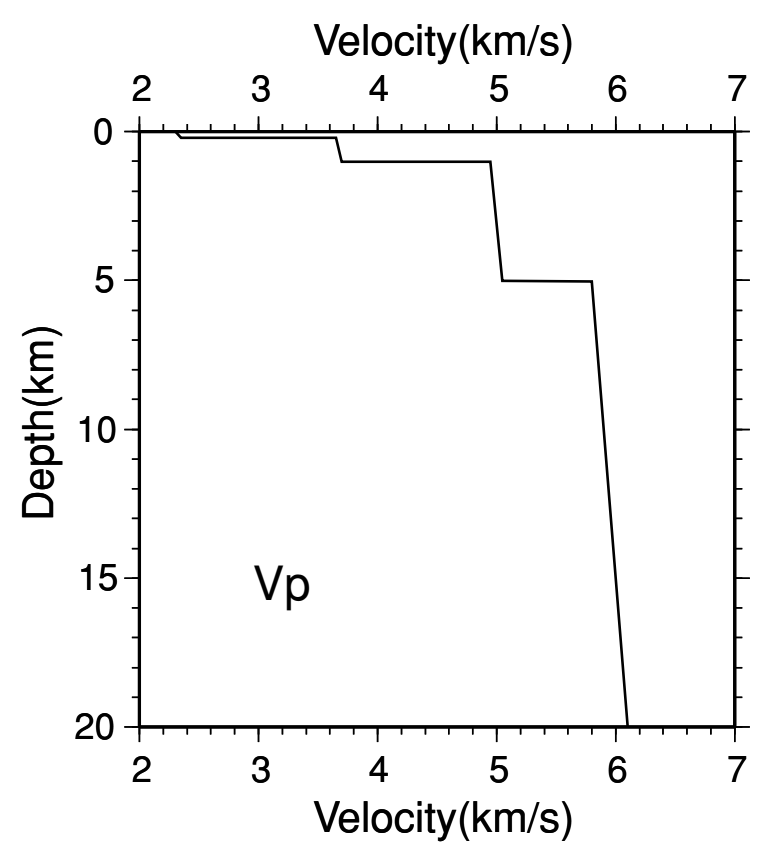

Fig. 3. Velocity model employed in the earthquake relocation.

\section{Aftershock Distributions and Spatial Varia- tions of Station Corrections}

Figure 5 shows the epicenter distributions of relocated aftershocks. Most of the epicenters are aligned along the fault-strike $\left(\mathrm{N} 35^{\circ} \mathrm{E}\right)$. However, epicenters of aftershocks in the southwestern region are aligned along $\mathrm{N} 15^{\circ} \mathrm{E}$, and rotate approximately $20^{\circ}$ counterclockwise from the faultstrike (I-J and K-L in Fig. 5). This rotation of the aftershock alignments coincides with the rotation of anticline axes (HA and TA in Fig. 5) in the southwestern area of the source region. This indicates that the surface geological structures such as anticlines or synclines observed in the source region are related to deep crustal movements associated with the mainshock rupture.

The depth sections of aftershocks reveal that the mainshock and the largest aftershock occurred on two $60^{\circ}$ westward-dipping planes, located approximately $5 \mathrm{~km}$ apart (Fig. 6). Conversely, the Oct. 27 event occurred on an eastward dipping plane with a dip angle of $25^{\circ}$ that was conjugate to the mainshock fault plane. The aftershock distributions are similar to those revealed by previous studies (e.g., Sakai et al., 2005; Shibutani et al., 2005). The dip angles of aftershock alignments associated with the three events are consistent with focal mechanisms determined by NEID (Fig. 5).

Other planes associated with moderate-magnitude aftershocks dip to the west or east. For example, along the crosssection of G-H in Fig. 6, one of the eastward-dipping planes can be seen near the bottom edge of the mainshock fault plane (outlined by broken ellipse). These estimated planes are conjugate to the mainshock fault plane. Furthermore, most of aftershocks at both northeastern and southwestern edges occurred at shallow depths with eastward-dipping planes (A-B, C-D, I-J in Fig. 6). At the northeastern edge, aftershocks are concentrated at shallower depths than those at the southwestern edges. Reliable description about these
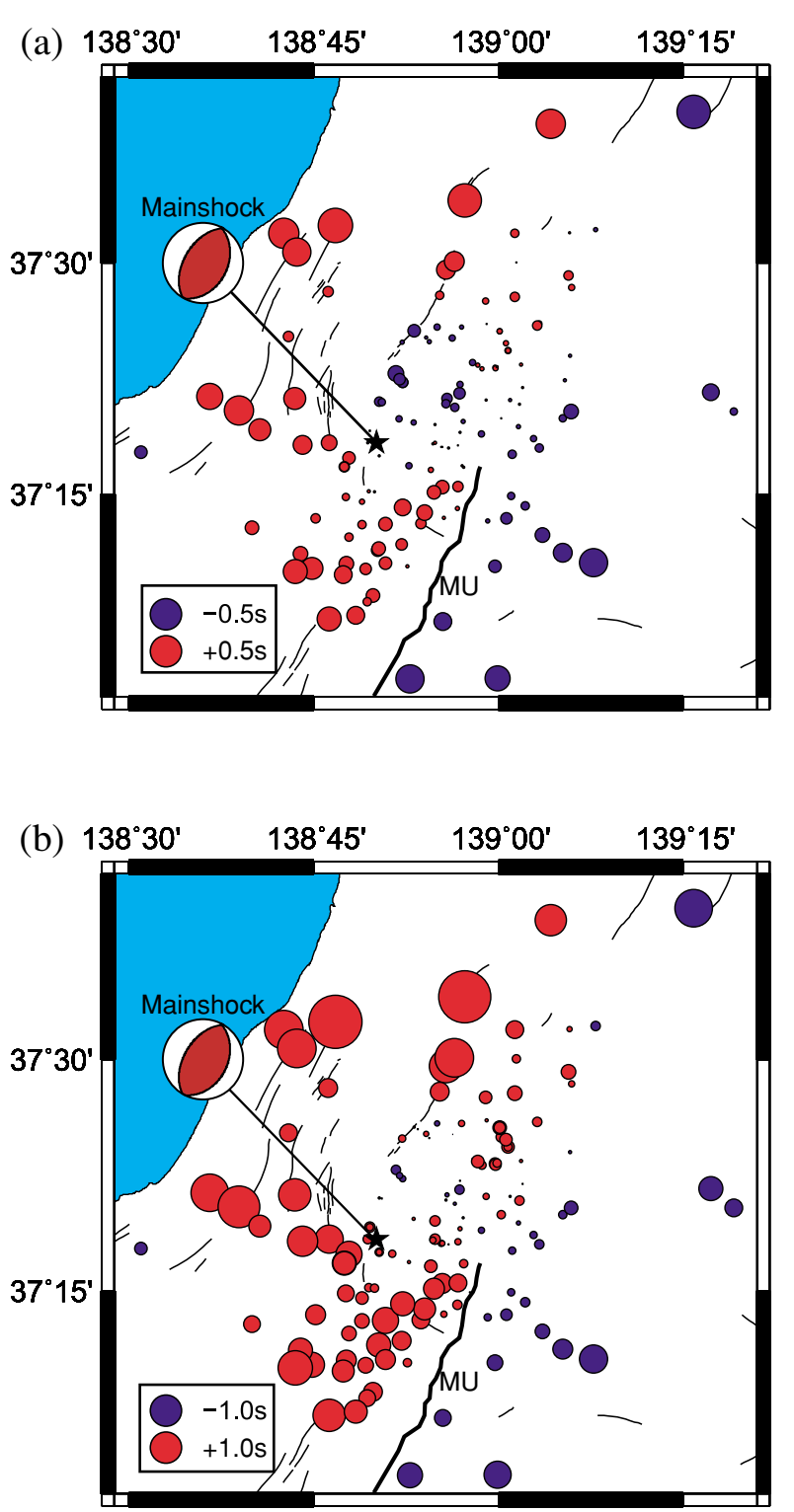

Fig. 4. Maps of the station-corrections for each seismic station. (a) Station-corrections for $P$-wave. (b) Station-corrections for $S$-wave. The Muikamachi fault (MU) is shown by thick solid line, and the other major active faults are drawn as thin lines.

aftershocks aligned on the eastward-dipping planes has not yet been given in the previous studies.

We compared the distributions of hypocenters determined by the present study with ones by a previous study (Sakai et al., 2005). The whole hypocenter distribution is similar between those two studies. A centroid of the hypocenter distribution in the present study is, however, shifted by approximately $0.5 \mathrm{~km}$ in the horizontal eastward and $1.1 \mathrm{~km}$ shallower, because of the different velocity structures adopted in the hypocenter relocation for each study.

Figure 4 shows the distributions of the station-corrections estimated for $P$ - and $S$ - waves. Each station-correction reflects velocity structure not only at the vicinity of a station, but also along ray-paths from aftershocks to the station. If station-corrections vary from station to station in a region, we can infer the heterogeneities in the velocity structure to 


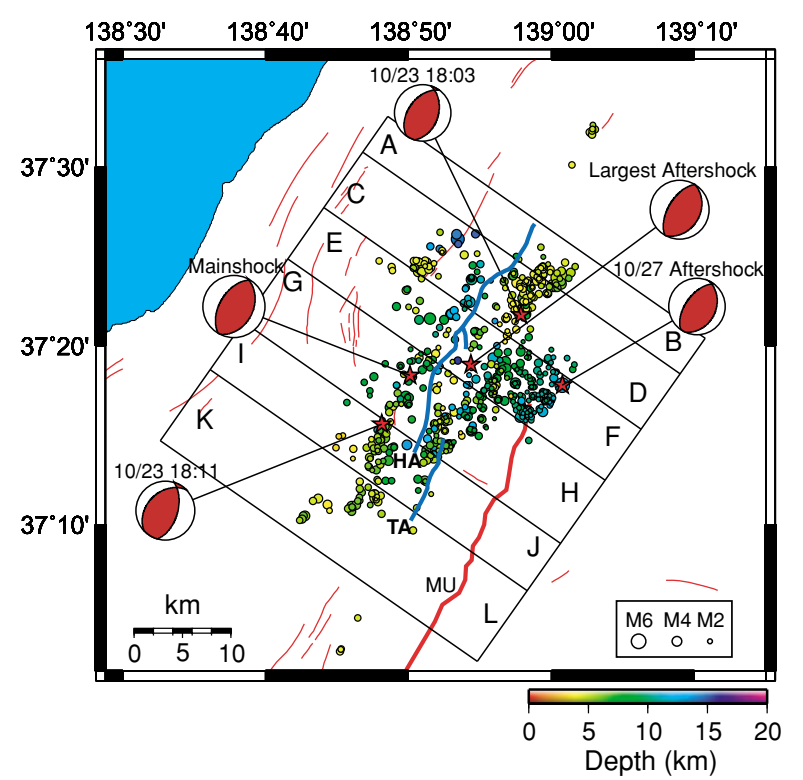

Fig. 5. Map of the relocated aftershock hypocenters (circles) determined by the double-difference earthquake algorithm. Size and color of the circles denote earthquake magnitude and depth. The five stars denote epicenters: mainshock; largest aftershock $\left(M_{\mathrm{w}}=6.3\right.$, Oct. 23$) ; M_{\mathrm{W}}=5.9$ aftershock (Oct. 23 18:03); $M_{\mathrm{w}}=5.7$ aftershock (Oct. 23 18:11); and the $M_{\mathrm{w}}=5.8$ aftershock (Oct. 27). Moment tensors are from the NIED catalog. The Muikamachi fault (MU) is shown by thick red line, and the other major active faults are drawn as thin red lines. Blue lines show the location of anticlines of Higashiyama (HA) and Tamugiyama (TA) (Takeda et al., 2006).

some extent. From Fig. 4, it is clearly observed that stationcorrections for $P$ - and $S$ - waves are largely positive at the western side of the Muikamachi-fault and its northeastward extension. In contrast, the station-corrections are negative at the eastern side. These results indicate that the average velocity in the hanging wall of the mainshock fault is lower than that in the foot wall. This result is consistent with seismic three-dimensional tomography studies which showed that the seismic velocities in the hanging wall on the western side were lower than those in the footwall on the eastern side (Kato et al., 2005a; Okada et al., 2005).

Note also that the station-corrections in the hanging wall of western side in the aftershock area vary along the faultstrike. Station-corrections are small and negative in the central area northeast of the mainshock epicenter, while they are large and positive in the area southwest of the epicenter. In the central area, large amount of seismic moment were released during the mainshock (e.g., Hikima and Koketsu, 2005). These results suggest that the average velocity of the mainshock rupture area (central area) is higher than the periphery of the source region in the hangingwall, especially compared with the southwestern side of the hypocenter. It is worthwhile to note that these variations of the velocity structures in the hanging wall along the fault strike are fairly consistent with those imaged by the three-dimensional tomography analysis (Kato et al., 2005a; Okada et al., 2005).

\section{Conclusions}

We deployed the extremely dense seismic network consisting of 145 seismic stations around the thrust fault associated with the 2004 mid-Niigata Prefecture Earthquake.

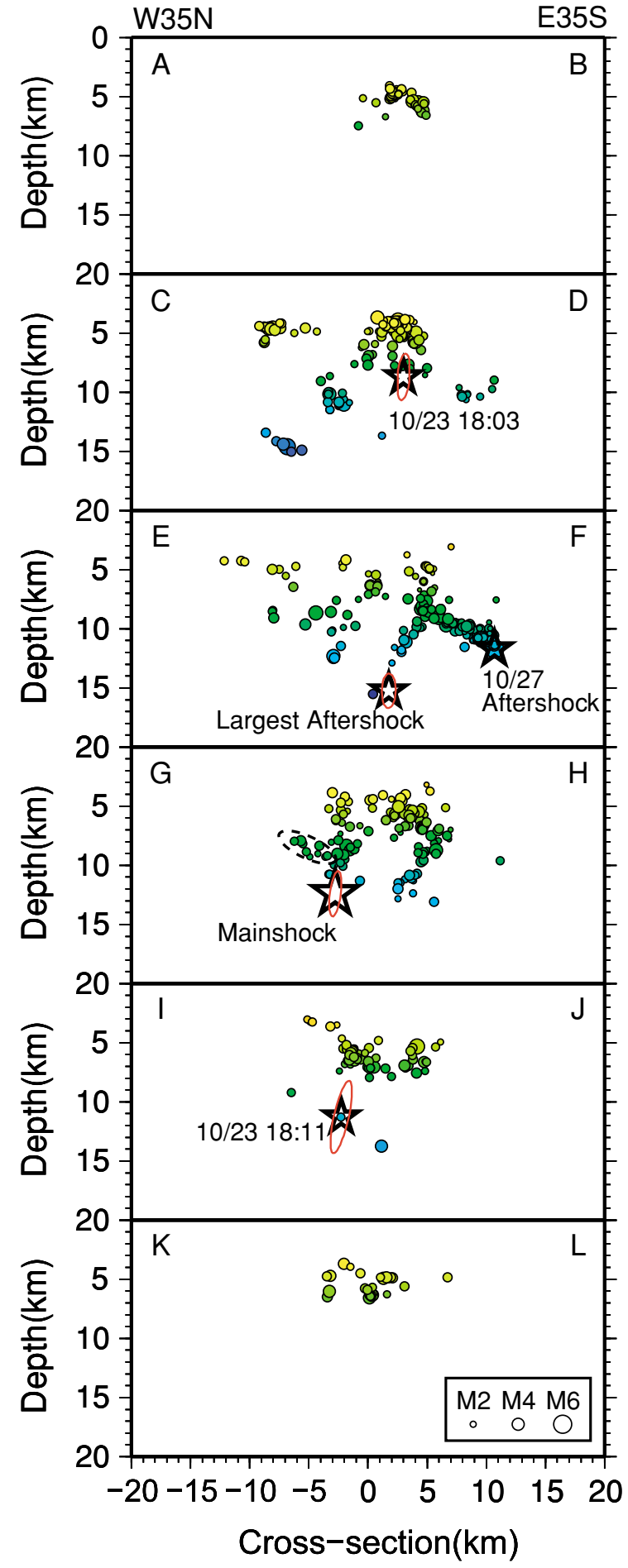

Fig. 6. Depth sections of relocated aftershocks. The sizes and colors of the circles are scaled to the magnitude, and the depth, respectively. Each section corresponds to the rectangle area drawn in Fig. 5. The strike of the cross section is $55^{\circ}$ from north to west, which is selected to be perpendicular to the direction of the mainshock fault-strike. Four large events on Oct. 23 are shown by stars with error ellipsoids (Kato et al., 2005b).

We obtained the highly accurate hypocenters by the doubledifference earthquake relocation algorithm. Relative location errors in the horizontal and vertical directions are estimated to be $40 \mathrm{~m}$ and $80 \mathrm{~m}$, respectively. Such hypocenters with high-accuracy are expected to be useful seismic sources to image the detailed crustal heterogeneities asso- 
ciated with the mainshock generation process. The depth sections of aftershocks reveal that the mainshock and the largest aftershock occurred on two $60^{\circ}$ westward-dipping planes, located approximately $5 \mathrm{~km}$ apart. Conversely, the Oct. 27 event occurred on an eastward dipping plane with a dip angle of $25^{\circ}$ that was conjugate to the mainshock fault plane. Most of aftershocks at both northeastern and southwestern edges occurred at shallow depths with eastwarddipping planes. Epicenters of aftershocks in the southwestern region are aligned along $\mathrm{N} 15^{\circ} \mathrm{E}$, and rotate approximately $20^{\circ}$ counterclockwise from the strike of the mainshock fault. This rotation of the aftershock alignments coincides with the rotation of anticline axes in the southwestern area of the source region. It should be noted that the distributions of station-corrections are consistent with the crustal structures imaged by the three-dimensional tomography analysis.

Acknowledgments. We appreciate to F. Waldhauser for use of the hypoDD code. We are grateful to two anonymous reviewers for their constructive comments, which led to substantial improvements to the original manuscript. We thank the National Research Institute for Earth Science and Disaster Prevention, Japan Meteorological Agency for allowing us to use the waveform data collected by their permanent stations. Most of the figures were created using GMT (Wessel and Smith, 1995). This work was partly supported by the Special Coordination Funds for the Promotion of Science and Technology offered by the Ministry of Education, Culture, Sports, Science and Technology of Japan (MEXT) under the title of Urgent Research for the 2004-Niigata Prefecture Earthquake, and a grant offered under the Earthquake Prediction Research program of MEXT.

\section{Appendix. Author list in alphabetical sequence}

Masakatsu Arao, Keisuke Ariyoshi, Youichi Asano, Keiji Doi, Bogdan Enescu, Shinya Fujieda, Hiroko Hagiwara, Toshio Haneda, Akira Hasegawa, Shin'ichi Hashimoto, Satoshi Hirahara, Naoshi Hirata, Yasuhiro Hirata, Issei Hirose, Shusaku Hondo, Kumiko Hori, Shuichiro Hori, Shigeki Horiuchi, Toshihiko Igarashi, Takashi Iidaka, Yoshihisa Iio, Ryoya Ikuta, Takeo Ito, Takaya Iwasaki, Aya Kamimura, Toshihiko Kanazawa, Yasuyuki Kano, Hiroshi Katao, Satoshi Kawamoto, Tomonori Kawamura, Saeko Kita, Masaru Kobayashi, Yuhki Kohno, Toshio Kono, Masahiro Kosuga, Atsuki Kubo, Eiji Kurashimo, Satoshi Matsumoto, Takeshi Matsushima, Toru Matsuzawa, Noa Mitsui, Reiko Miura, Masatoshi Miyazawa, Tomoko Mizukami, Satoko Murotani, Satoru Nagai, Junichi Nakajima, Takashi Nakayama, Hiroaki Negishi, Kinya Nishigami, Izumi Ogino, Shiro Ohmi, Tomomi Okada, Hiroki Onaha, Shantha S.N. Gamage, Mamoru Saka, Shin'ichi Sakai, Katsuhito Sato, Toshiya Sato, Masato Serizawa, Takuo Shibutani, Junpei Shimizu, Junichi Suganomata, Kiyoko Tagami, Keisuke Takahashi, Kaori Takai, Fumiaki Takeuchi, Yasuda Takumi, Kazuo Tanaka, Ken'ichi Tatsumi, Takashi Tonegawa, Hiroaki Tsushima, Naoki Uchida, Kenji Uehira, Tomotake Ueno, Norihito Umino, Hiroo Wada, Kazutoshi Watanabe, Shigeru Watanabe, Yasuo Yabe, Tadashi Yaginuma, Mamoru Yamada, Shunroku Yamamoto, Yoshiko Yamanaka, Futoshi Yamashita, Fumihito Yamazaki, Satoshi Yui, Yohei Yukutake

\section{References}

Aoki, S., M. Nishi, K. Nakamura, T. Hashimoto, S. Yoshikawa, and H. M. Ito, Multi-planar structures in the aftershock distribution of the Mid Niigata prefecture Earthquake in 2004, Earth Planets Space, 57, 411416, 2005.

Hikima, K. and K. Koketsu, Rupture processes of the 2004 Chuetsu (mid-Niigata prefecture) earthquake, Japan: A series of events in a complex fault system, Geophys. Res. Lett., 32, L18303, doi:10. 1029/2005GL023588, 2005.

Hirata, N. and M. Matsu'ura, Maximum-likelihood estimation of hypocenter with origin time eliminated using nonlinear inversion technique, Phys. Earth Planet. Inter., 47, 50-61, 1987.

Kato, A., E. Kurashimo, N. Hirata, T. Iwasaki, and T. Kanazawa, Imaging the source region of the 2004 Mid-Niigata prefecture earthquake and the evolution of a seismogenic thrust-related fold, Geophys. Res. Lett., 32, L07307, doi:10.1029/2005GL022366, 2005a.

Kato, A., S. Sakai, N. Hirata, E. Kurashimo, S. Nagai, T. Iidaka, T. Igarashi, Y. Yamanaka, S. Murotani, T. Kawamura, T. Iwasaki, T. Kanazawa, Short-term spatiotemporal variations in the aftershock sequence of the 2004 mid-Niigata prefecture earthquake, Earth Planets Space, 57, 551-556, 2005b.

Matsumoto, S., Y. Iio, T. Matsushima, K. Uehira, and T. Shibutani, Imaging of $S$-wave reflectors in and around the hypocentral area of the 2004 mid Niigata Prefecture Earthquake (M6.8), Earth Planets Space, 57, 557-561, 2005.

Okada, T., N. Umino, T. Matsuzawa, J. Nakajima, N. Uchida, T. Nakayama, S. Hirahara, T. Sato, S. Hori, T. Kono, Y. Yabe, K. Ariyoshi, S. Gamage, J. Shimizu, J. Suganomata, S. Kita, S. Yui, M. Arao, S. Hondo, T. Mizukami, H. Tsushima, T. Yaginuma, A. Hasegawa, Y. Asano, H. Zhang, and C. Thurber, Aftershock distribution and 3D seismic velocity structure in and around the focal area of the $2004 \mathrm{mid}$ Niigata prefecture earthquake obtained by applying double-difference tomography to dense temporary seismic network data, Earth Planets Space, 57, 435-440, 2005.

Sakai, S., N. Hirata, A. Kato, E. Kurashimo, T. Iwasaki, and T. Kanazawa, Multi-fault system of the 2004 Mid-Niigata Prefecture Earthquake and its aftershocks, Earth Planets Space, 57, 417-422, 2005.

Sato, H., The relationship between late Cenozoic tectonic events and stress field and basin development in northeast Japan, J. Geophys. Res., 99, 22261-22274, 1994.

Schaff, P. D., G. H. R. Bokelmann, W. L. Ellsworth, E. Zanzerkia, F. Waldhauser, and G. C. Beroza, Optimizing correlation techniques for improved earthquake location, Bull. Seismol. Soc. Am., 94, 705-721, 2004

Shearer, P., Improving local earthquake locations using the L1 norm and waveform cross correlation: application to the Whittier Narrows, California, aftershock sequence, J. Geophys. Res., 102, 8269-8283, 1997.

Shibutani, T., Y. Iio, S. Matsumoto, H. Katao, T. Matsushima, S. Ohmi, F. Takeuchi, K. Uehira, K. Nishigami, B. Enescu, I. Hirose, Y. Kano, Y. Kohno, M. Korenaga, Y. Mamada, M. Miyazawa, K. Tatsumi, T. Ueno, H. Wada, and Y. Yukutake, Aftershock distribution of the 2004 Mid Niigata Prefecture Earthquake derived from a combined analysis of temporary online observations and permanent observations, Earth Planets Space, 57, 545-549, 2005.

Takeda, T., H. Sato, T. Iwasaki, N. Matsuta, S. Sakai, T. Iidaka, and A. Kato, Crustal structure in the northern Fossa Magna region, central Japan, from refraction/wide-angle reflection data, Earth Planets Space, 56, 1293-1299, 2004.

Takeda, T., K. Yanagisawa, T. Sakai, R. Miyawaki, A. Miyawaki, M. Momose, S. Mukoyama, and H. Sasaki, Active geological structure and landforms in epicentral region of the mid Niigata prefecture earthquake in 2004, Zisin, 2nd Ser., 58, 413-426, 2006.

Urabe, T., A proposal for a common format for multi-channel seismic wave data, Prog. Abstr. Seismol. Soc. Jpn., 2, 384, 1994.

Waldhauser, F. and W. L. Ellsworth, A double-difference earthquake location algorithm: Method and application to the Northern Hayward fault, Bull. Seismol. Soc. Am., 90, 1353-1368, 2000.

Wessel, P. and W. H. F. Smith, New version of the generic mapping tools released, Eos Trans. AGU, 76, 329, 1995.

Yanagisawa, Y., I. Kobayashi, K. Takeuchi, M. Tateishi, K. Chihara, and H. Kato, Geological Sheet Map 1:50,000 “Ojiya”, Geological Survey of Japan, 1986.

A. Kato (e-mail: akato@eri.u-tokyo.ac.jp) and The Research Team of aftershock observations for the 2004 mid-Niigata Prefecture Earthquake 